Article

\title{
On the Physics of Machining Titanium Alloys: Interactions between Cutting Parameters, Microstructure and Tool Wear
}

\author{
Mohammed Nouari * and Hamid Makich \\ University of Lorraine, Laboratoire d'Énergétique et de Mécanique Théorique et Appliquée, \\ LEMTA CNRS-UMR 7563, GIP-InSIC, 27 rue d'Hellieule, St-Dié-des-Vosges, France; \\ E-Mail: hamid.makich@univ-lorraine.fr \\ * Author to whom correspondence should be addressed; \\ E-Mail: mohammed.nouari@univ-lorraine.fr; Tel.: +33-3-29-42-22-26; Fax: +33-3-29-42-18-25.
}

Received: 9 May 2014; in revised form: 19 June 2014 / Accepted: 30 June 2014 /

Published: 7 July 2014

\begin{abstract}
The current work deals with the analysis of mechanisms involved during the machining process of titanium alloys. Two different materials were chosen for the study: Ti-6Al-4V and Ti-55531. The objective was to understand the effect of all cutting parameters on the tool wear behavior and stability of the cutting process. The investigations were focused on the mechanisms of the chip formation process and their interaction with tool wear. At the microstructure scale, the analysis confirms the intense deformation of the machined surface and shows a texture modification. As the cutting speed increases, cutting forces and temperature show different progressions depending on the considered microstructure (Ti-6Al-4V or Ti-55531 alloy). Results show for both materials that the wear process is facilitated by the high cutting temperature and the generation of high stresses. The analysis at the chip-tool interface of friction and contact nature (sliding or sticking contact) shows that machining Ti55531 often exhibits an abrasion wear process on the tool surface, while the adhesion and diffusion modes followed by the coating delamination process are the main wear modes when machining the usual Ti-6Al-4V alloy.
\end{abstract}

Keywords: Titanium alloys; machinability; Ti-55531; Ti-6Al-4V; tool wear; microstructure; coating effect; lubrication effect; chip formation 


\section{Introduction}

Titanium alloys are widely used for applications requiring an excellent mechanical resistance and high strength at elevated temperature. This alloy has high mechanical characteristics that allow better performance on commercial aircraft, and a significant gain compared to the commonly used Ti-6Al-4V alloy. Beyond its interesting ratio density/mechanical properties, the Ti-55531 alloy provides significant benefits for the demanding environment of aeronautics. This comes from its ability to maintain mechanical properties at high temperature, the fatigue strength and its excellent corrosion resistance [1,2]. Clément et al. [3,4] have reported that the high level properties of titanium alloys depend on several strengthening mechanisms such as grain size, solid solution atoms, and precipitation hardening, which all can be tuned during the various forming processing steps, leading to particular microstructures.

In manufacturing production, titanium alloys are classified as hard to cut materials. The main problems encountered when machining titanium alloy are the low material removal rate and the short tool life because of the excessive wear exhibited during the chip formation process. The first findings of machining Ti-55531 alloy are manifested by low cutting speeds. This causes high cycle times and reduced tool life, and then generates an increase in manufacturing costs.

Titanium is chemically reactive and, therefore, has a tendency to weld to the cutting tool during machining leading to chipping and premature tool failure [5-7]. In addition, its low thermal conductivity (about $15 \mathrm{~W} / \mathrm{m} \mathrm{K}$ vs. $270 \mathrm{~W} / \mathrm{m} \mathrm{K}$ for the steel CRS1018 at $700{ }^{\circ} \mathrm{C}$ ) increases the temperature at the tool/workpiece interface, which adversely affects the tool life. Additionally, the high strength maintained at elevated temperature and low modulus of elasticity $(50 \%$ less than that of the steel) further impairs the machinability of these materials [6-9]. According to Ezugwu [10], the tool wear in machining of titanium alloys is due to high stresses and high temperatures found near to the cutting edge. The same conclusions were made by Subramanian [11].

From a microstructural point of view, elemental titanium presents an allotropic phase transformation at $880^{\circ} \mathrm{C}$ between the body centered cubic (bcc) and hexagonal close packed structures stable at high and low temperatures, respectively. The two phases of titanium alloys are known as $\alpha$ phase and $\beta$ phase respectively [12]. Combinations of working and heat treatment alter the microstructure and change the mechanical properties of the metal. The microstructure and properties can also be affected by adding other elements to titanium. Addition of other elements to pure titanium, i.e., alloying, can alter microstructure and properties as well. Depending on which phase is to be dominant in a particular alloy $(\alpha, \beta$ or $\alpha+\beta)$ an alloying element (or group of elements) may be added to pure titanium [3-5]. Thus, one way of classifying alloying elements is according to whether they are $\alpha$ or $\beta$ stabilizers. Alpha stabilizers are soluble in the $\alpha$-phase and many act as solid solution strengtheners while also increasing the temperature at which the $\alpha$-phase is stable. Alpha stabilizers include such elements as $\mathrm{Al}, \mathrm{Ga}, \mathrm{Sn}, \mathrm{Ge}$, and La. Beta stabilizing elements decrease the $\beta$ transus (i.e., the temperature at which the material transforms to $100 \% \beta$-phase). As such, these elements increase the range over which the $\beta$-phase is stable. Beta stabilizers may be isomorphous or eutectoid. Isomorphous elements (such as $\mathrm{V}, \mathrm{Mo}, \mathrm{Nb}, \mathrm{Ta}$, and $\mathrm{Re}$ ) are soluble in the $\alpha$-phase while eutectoid elements like ( $\mathrm{Cr}, \mathrm{Fe}, \mathrm{Mn}, \mathrm{Cu}, \mathrm{Ag}, \mathrm{Au}, \mathrm{Ni}$, and $\mathrm{Co}$ ) create a eutectoid phase. 
According to Fanning [13], Ti-55531 (TIMETAL 555) is a high-strength near- $\beta$ titanium alloy that was designed for improved productivity and excellent mechanical property combinations, including deep hardenability especially in aeronautical and aerospace industries. According to the same author and to Clément et al. in $[3,4]$, this recent alloy was designed based on the older Russian alloy VT22 to primarily fulfill high-strength forging applications. A lower-strength state with improved toughness and damage tolerance is under consideration for other parts of aircraft structure [14]. However, being of recent origin, there is a lack of information on machining of this alloy. This is despite the existence of information regarding thermomechanical processing of this family of alloys [15], and the abundance of information available regarding machining of titanium and some of its alloys (notably Ti-6Al-4V) [16]. In the machining field, it is well known that titanium and titanium alloys are hard-to-cut materials. This means that Ti-55531 will most likely present engineers with many technical problems to be solved in order to produce net shape components. Bouchnak recently proposed in [12] a study on the machinability of this material and assistance techniques to enhance the machining process. However, according to the literature in the field of machining, the state of the art does not present optimal solutions or does not give the real parameters that influence the cutting forces and tool wear (cutting conditions, tool geometry, and cutting material).

In order to increase productivity and tool-life in machining of titanium alloys, it is necessary to study the chip formation process and its effect on the physical cutting parameters and the material cutting performance. The objective of this study is to understand the poor machinability of titanium alloys especially the Ti-55531 one which exhibits extreme tool wear and unstable cutting forces.

\section{Experimental Section}

\subsection{Titanium Alloys}

To analyze the machinability of the titanium alloys Ti-6Al-4V and Ti-55531, a parametric study was conducted through several orthogonal cutting tests (cutting tests). The chip formation and tool wear processes were investigated particularly in terms of cutting parameters such as cutting forces, friction coefficient and cutting temperature,. Tests were carried out on a heavy-duty lathe machine with an $11 \mathrm{~kW}$ motor drive, which generates a maximum torque of $1411 \mathrm{Nm}$. The spindle rotational speed ranges from 18-1800 rpm.

As mentioned above, two alloys were chosen for machining experiments. The first one was the alloy Ti-6Al-4V, considered as the reference for these tests. It is characterized with duplex structure $\alpha /(\alpha+\beta)$, and average grain size around $10 \mu \mathrm{m}$ (range from 5-20 $\mu \mathrm{m}$ ). The second alloy studied here is the Ti-55531 with average grain size around $1 \mu \mathrm{m}$ (range from $0.5-5 \mu \mathrm{m}$ ).

Figure 1a-d depict the microstructure of each workpiece alloy before machining. The initial microstructure of the Ti-6Al-4V alloy, Figure 1a,b, consists of single phase $\alpha$ matrix. Inclusions of $\beta$ grains can also be seen with average grain size of $10 \mu \mathrm{m}$ (range of 5-20 $\mu \mathrm{m}$ ). Similarly, the initial microstructure of the $\beta$ alloy Ti-55531 is shown in Figure 1c,d. The microstructure consists of single phase $\beta$ matrix with average size of $\alpha$ grains of $5 \mu \mathrm{m}$ (range $1-5 \mu \mathrm{m}$ ). 
In this work it was found that the lamellar structure can be observed in $\alpha+\beta$ colonies (transformed $\beta$ ); particularly for the Ti-6Al-4V alloy. Figure 1a shows the localization of the lamellar structure. This was previously confirmed by the work of Benedetti and Fontanari in [17].

Figure 1. Microstructure of the workpiece material used in the current study before machining. (a,b), $\alpha+\beta$ alloy Ti-6Al-4V; (c,d), $\beta$ alloy Ti-55531.

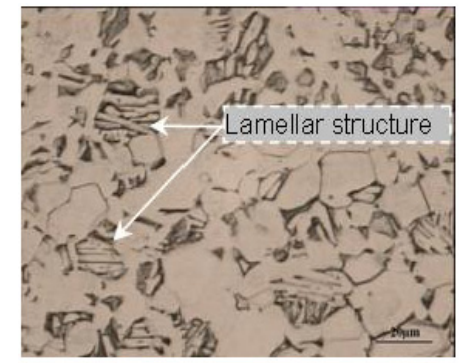

(a) Optical micrograph of Ti-6Al-4V

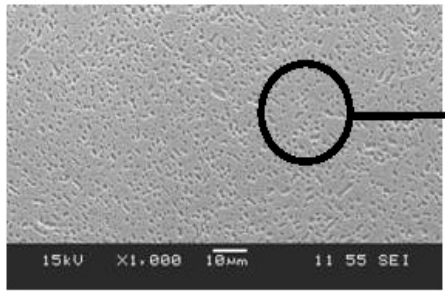

(c) SEM micrograph of Ti-55531

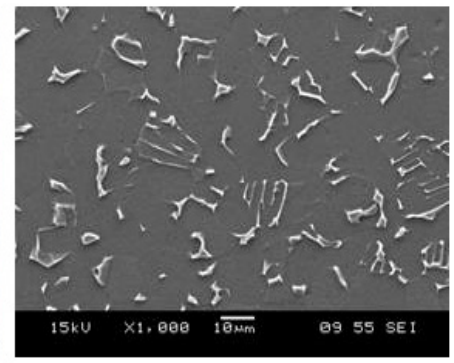

(b) SEM micrograph of Ti-6Al-4V

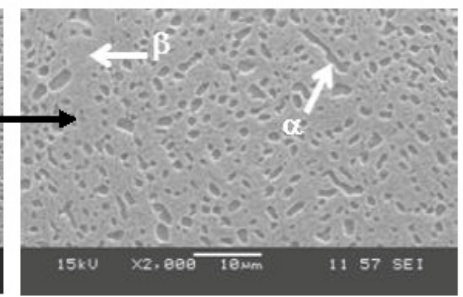

(d) High magnification of SEM micrograph of Ti-55531

Table 1 presents a summary of the chemical composition of both alloys. According to Bouchnak [12], Fanning [13] and Nouari et al. [18] the physical properties of the Ti-6Al-4V and Ti-55531 alloys are summarized in Table 2.

Table 1. Chemical composition of machined titanium.

\begin{tabular}{ccc}
\hline Chemical element & Ti-6Al-4V (wt.\%) & Ti-55531 (wt.\%) \\
\hline $\mathrm{Al}$ & 5.5 & 5 \\
$\mathrm{~V}$ & 3.8 & 5 \\
$\mathrm{Fe}$ & Max 0.8 & 0.3 \\
$\mathrm{Mo}$ & 0 & 5 \\
$\mathrm{Cr}$ & 0 & 3 \\
$\mathrm{Nb}$ & 0 & $0.5-1.5$ \\
$\mathrm{Zr}$ & 0 & $0.5-1.5$ \\
\hline
\end{tabular}

To complete the characterization of studied titanium alloys, tests of Vickers hardness were performed on different specimens at room temperature. The micro-hardness of the Ti-6Al-4V specimen was found to be about $317 \mathrm{HV}_{0.2}$ and that measured for the Ti-55531 alloy to be about $379 \mathrm{HV}_{0.2}$. Ti-55531 is therefore $20 \%$ harder than Ti-6Al-4V. This result confirms the hard nature of the Ti-55531 microstructure, which will have a direct effect on its machinability, i.e., the level of cutting forces, tool wear, cutting temperature, etc. 
Table 2. Mechanical and thermal properties of Ti-6Al-4V and Ti-55531.

\begin{tabular}{ccc}
\hline Thermal and mechanical properties & Ti-6Al-4V & Ti-55531 \\
\hline$\beta$ transus $\left(\mathrm{T}_{\beta}\right)\left({ }^{\circ} \mathrm{C}\right)$ & 980 & 856 \\
Density $\left(\mathrm{g} / \mathrm{cm}^{3}\right)$ & 4.43 & 4.65 \\
Tensile elastic modulus $(\mathrm{GPa})$ & 110 & 112 \\
Compressive elastic modulus $(\mathrm{GPa})$ & -- & 113 \\
Tensile strength $(\mathrm{MPa})$ & 931 & 1236 \\
Yield strength $(\mathrm{MPa})$ & 862 & 1174 \\
Elongation $(\%)$ & 14 & 6 \\
Thermal conductivity at $20^{\circ} \mathrm{C}(\mathrm{W} / \mathrm{m} \mathrm{K})$ & 7.3 & 6.2 \\
Specific heat $20-100^{\circ} \mathrm{C}(\mathrm{J} / \mathrm{Kg} \mathrm{K})$ & 709 & 495 \\
\hline
\end{tabular}

\subsection{Cemented Carbide Tools}

In this study, inserts made of cemented tungsten carbide (WC-Co) were used. The effect of the coating on the tool wear under extreme loading conditions was also investigated. To do that, a comparative study was performed between uncoated tool and coated one using a single layer of TiAlN coating with average thickness of $4 \mu \mathrm{m}$.

The TiAlN coating has a strong chemical stability, a low thermal conductivity and a high oxidation wear resistance at $900{ }^{\circ} \mathrm{C}$. The TiAlN coating increases the surface hardness to approximately 3400-3600 $\mathrm{Hv}$ and improves the resistance to abrasive wear. The thermal conductivity of this coating is about $10 \mathrm{~W} / \mathrm{m} \mathrm{K}$ (at $20^{\circ} \mathrm{C}$ ). Devillez et al. [19] state that TiAlN coating imparts an excellent crater resistance. Additionally, Singh et al. [20] and Castanho et al. [21] show that the Al element incorporated in TiAlN coating forms the superficial layer $\mathrm{Al}_{2} \mathrm{O}_{3}$ to improve the wear resistance and to enhance the chemical stability.

Therefore, the cutting tools used in these machining tests were made of tungsten carbide with cobalt binder, Grade H13A (WC-6\% Co, type K20). The tool microstructure is shown in Figure 2a. Average and maximum sizes of the WC grains are respectively $1 \mu \mathrm{m}$ and $5 \mu \mathrm{m}$. The average percentage of cobalt is about $6 \%$, the analysis under a scanning electron microscope (SEM) revealed that the Co binder is uniformly distributed in the tool surface, Figure $2 b$. Table 3 presents a summary of the mechanical and thermal properties of cutting tools.

Table 3. Mechanical and thermal properties of the cutting tool substrate [5-9].

\begin{tabular}{cc}
\hline Tool substrate & WC-6\%Co \\
\hline Hardness $25^{\circ} \mathrm{C}\left(\mathrm{HV}_{10}\right)$ & 1485 \\
Hot hardness $800^{\circ} \mathrm{C}\left(\mathrm{kg} / \mathrm{mm}^{2}\right)$ & 600 \\
Density $\left(\mathrm{g} / \mathrm{cm}^{3}\right)$ & 11.4 \\
Thermal conductivity $(\mathrm{W} / \mathrm{mK})$ & 45 \\
Thermal expansion $\left(10^{-6} / \mathrm{K}\right)$ & 6.1 \\
Modulus of elasticity $(\mathrm{GPa})$ & 620 \\
Traverse rupture $(\mathrm{GPa})$ & 2.2 \\
Poisson coefficient $v$ & 0.26 \\
\hline
\end{tabular}


Figure 2. SEM micrograph of cemented carbide tool (WC-6\% Co).
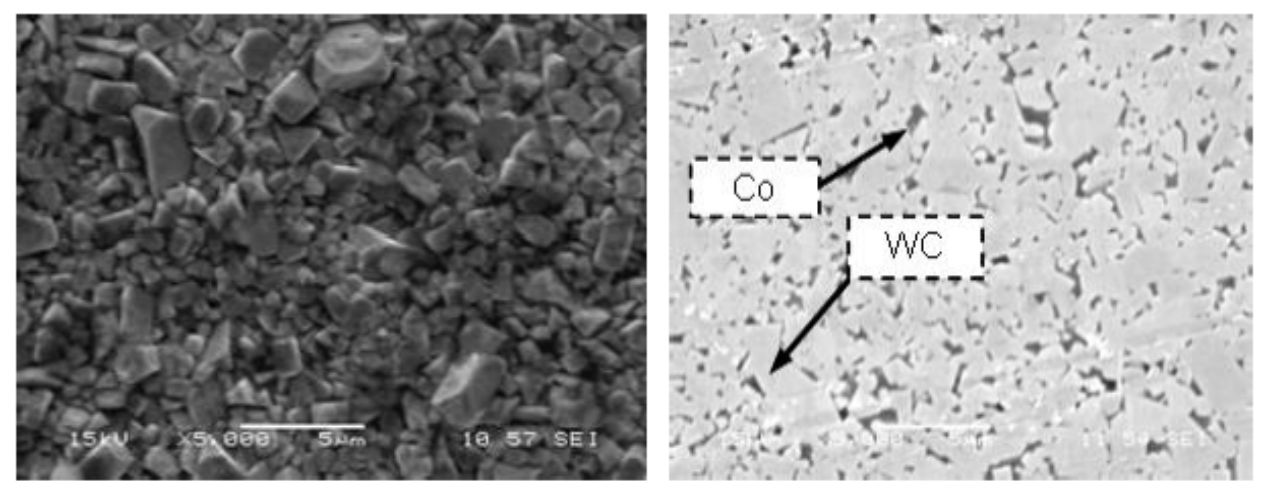

\subsection{Cutting Tool Geometry and Cutting Parameters}

Concerning the tool geometry, a special designed tool (with two different geometries) was considered in these experiments. Figure 3 shows the two geometries used in the study. The first geometry is more conventional without a particular treatment on the cutting edge, designated by geometry "A" (Figure 3a). The second geometry is characterized by an additional angle of the cutting edge, designated by geometry "B" (Figure $3 b$ ).

Figure 3. Presentation of the tool geometries used in machining tests.

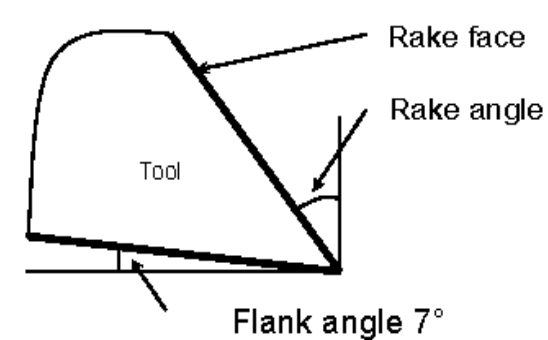

(a) Tool A, Rake angle constant along the rake face

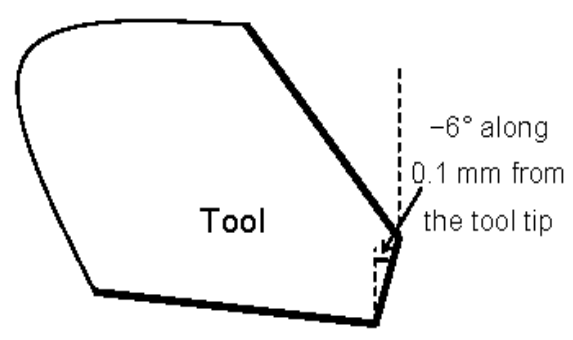

(b) Tool B, two different rake angles along the cutting edge

Tools for orthogonal cutting (width $4.45 \mathrm{~mm}$ ) have one cutting edge and the flank angle is about $7^{\circ}$. Also, the tool "A" has a rake angle of $20^{\circ}$ and the tool "B" has a rake angle of $0^{\circ}$ and an additional angle of $-6^{\circ}$ along $0.1 \mathrm{~mm}$ from the tool tip. This beveled edge helps to improve the tool strength. The tool geometries were tested for both materials in the study under orthogonal machining configuration.

To determine the lubrication influence on the tool wear when machining titanium alloys, experimental tests were performed with and without lubrication. These investigations are added to the analysis of the influence of the material microstructure, tool geometry and coating on titanium alloys machinability. However, machining is a manufacturing process with a large number of interacting variables. The produced geometry is influenced by many variables, such as cutting speed, feed, depth of cut, etc. Therefore, the cutting conditions of Table 4 have been taken into account to achieve a parametric study on orthogonal cutting. 
Table 4. Cutting conditions.

\begin{tabular}{cc}
\hline Cutting speed $\boldsymbol{V}_{\mathbf{c}}(\mathbf{m} / \mathbf{m i n})$ & $\mathbf{2 0 , 3 5}$ and $\mathbf{6 5}$ \\
\hline Feed $\mathrm{f}(\mathrm{mm} / \mathrm{rev})$ & 0.1 \\
Flank angle $\left(^{\circ}\right)$ & $7^{\circ}$ \\
Rake angle $\left(^{\circ}\right)$ & $0^{\circ}$ and $20^{\circ}$ \\
\hline
\end{tabular}

Thus, all these parameters (cutting conditions, tool coating and geometry and lubrication) were considered as wear factors in this work to investigate the influence of cutting forces, friction coefficient, cutting temperature, and chip formation process on tool wear.

As shown by Table 4, experiments were carried out keeping cutting speed and rake angle at various levels. The range of each factor was selected based on present day industrial requirements. The cutting length allowed by the machine capacity (about $1.5 \mathrm{~m}$ ) provides a sufficient cutting time to reach a stationary regime of the cutting process ( $1.6 \mathrm{~s}$ for a cutting speed of $65 \mathrm{~m} / \mathrm{min}$ ).

All experiments were carried out with a constant width of $3.5 \mathrm{~mm}$. The other variables such as machine condition, variability in set up, etc. were maintained constant throughout the experimentation. A three component $\mathrm{Kistler}^{\circledR}$ dynamometer was employed for cutting force measurements (cutting force and feed force).

\section{Thermal Characterization of Titanium Alloys and Monitoring of the Chip Formation Process}

\subsection{Temperature Measurements}

The cutting temperature was estimated using two techniques: the first technique is based on measurements with an infrared camera (Cedip camera, Cedip Infrared Systems, Croissy-Beaubourg, France); and the second technique is based on an inverse measurement method using a thermistor located behind the cutting tool edge. The last technique was developed previously by Battaglia et al. in [22].

The infrared camera provides the thermal field directly which only gives an assessment of temperature levels. This technique allows a qualitative analysis, unfortunately it cannot be used to determine with high precision the temperature values on the cutting tool surface. This is due on the one hand to the complexity of the instrumentation, and on the other hand to the confinement of the contact area between tool, chip and workpiece. Table 5 presents mean values of the cutting temperature in the case of machining Ti-55531. These measurements were performed using two different cutting speeds $(V=20 \mathrm{~m} / \mathrm{min}$ and $V=65 \mathrm{~m} / \mathrm{min})$.

Table 5. Mean temperature obtained by infrared camera technique (Cedip camera) when machining Ti-55531 with tool "A", rake angle $20^{\circ}$.

\begin{tabular}{cc}
\hline Cutting speed (m/min) & Temperature $\left({ }^{\circ} \mathbf{C}\right)$ \\
\hline 20 & 628 \\
65 & 761 \\
\hline
\end{tabular}

In contrast to the first technique, the second method uses thermistors and provides an indirect measurement of the cutting temperature (Table 6). The thermistor (very small thermocouple with 
diameter $d=470 \mu \mathrm{m}$ ) is placed in a hole made by the electroerosion process inside the tool without embrittlement of its integrity. Thermistors are held fixed close to the cutting tool face. This makes it possible to obtain measurements of the heat flux transmitted to the cutting tool. Using the inverse model, developed by Battaglia et al. in [22], an average temperature can be obtained with the measured heat flux taken as an input parameter of the model. We recall here that this type of measurement cannot be performed in the case of lubricated machining to avoid disturbance of the thermal field.

Table 6. Estimated temperatures during machining of Ti-55531 using thermistors. Tool "A", rake angle $20^{\circ}$.

\begin{tabular}{cc}
\hline Cutting speed (m/min) & Temperature $\left({ }^{\circ} \mathbf{C}\right)$ \\
\hline 20 & 450 \\
65 & 800 \\
\hline
\end{tabular}

As a conclusion on the temperature measurements study, it can be said that whatever the used cutting speed, no phase transition should be expected, since the corresponding cutting temperature remains less than the $\beta$ transus of titanium alloys, which is about $880{ }^{\circ} \mathrm{C}$.

Therefore no phase transition occurs in the microstructure, confirming the assumption of Puerta Velasquez et al. in [23]. The latter reported that only severe shearing takes place in the titanium material during machining.

\subsection{Thermal Conductivity Measurements}

Before starting the analysis, it is very important to remind ourselves of the evolution of thermal conductivities for the considered titanium alloys with temperature (Figure 4). This has an impact directly on the evolution of tool wear. The data used for plotting Figure 4, were obtained by measuring thermal conductivities using the "Hot Disk" method for several specimens under different temperatures [24]. The high temperatures were close to those obtained during machining of the same materials.

Figure 4. Evolution of thermal conductivities of Ti-55531 and Ti-6Al-4V with cutting temperature.

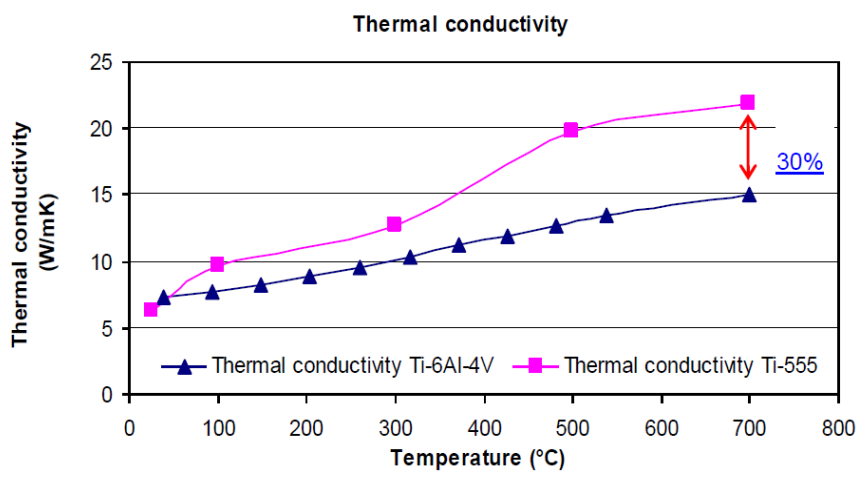

Ti-55531 and Ti-6Al-4V alloys show a clear difference of about $30 \%$ in their thermal conductivities at $700{ }^{\circ} \mathrm{C}$ (Figure 4). At high temperatures, the Ti-55531 alloy conducts heat better than the Ti-6Al-4V alloy. This result is very interesting since it allows us to explain the morphology observed of formed 
chips and the variation in cutting forces. Indeed, a low thermal conductivity promotes chip segmentation and thus a reduction of the machining efforts; this is the case for Ti-6Al-4V alloy, [25]. When the thermal conductivity increases, the heat stored in the machined material is discharged to the chip and then the ability of the machined material to soften is reduced. Under these conditions, the machining efforts will not fall because of the material flow stress which remains high even at very high temperatures, as in the case for the Ti-55531 alloy. Based on these findings, the degradation modes of the cutting tool could be of a mechanical type for Ti-55531 (abrasion mode) and physico-chemical for Ti-6Al-4V (adhesion and diffusion modes).

\subsection{Monitoring of the Chip Formation Process}

The study of the formation and the nature of chips is one of the parameters used to characterize the machining. Due to the fact that the machining process is very fast even at low cutting speeds, a high-speed camera (CCD) is used for viewing and monitoring chip formation (Figure 5). The camera used in this study is a Phantom ${ }^{\circledR}$ (Phaedrusfilms, Inc., New York City, NY, USA). The maximum resolution is $512 \times 512$. The acquisition in terms of frame number per second is up to $11,000 \mathrm{frames} / \mathrm{s}$. The analysis of different sequences give important information about the physical parameters of machining: worn contact length, deformation level, chips morphology, etc.

Figure 5. Chip formation; (a) morphology, $V_{\mathrm{c}}=20 \mathrm{~m} / \mathrm{min}$, rake angle $0^{\circ}$, (b) segmentation process, $V_{\mathrm{c}}=65 \mathrm{~m} / \mathrm{min}$, rake angle $0^{\circ}$.

(a)

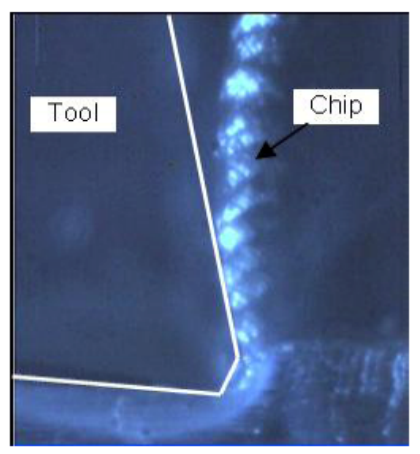

(b)

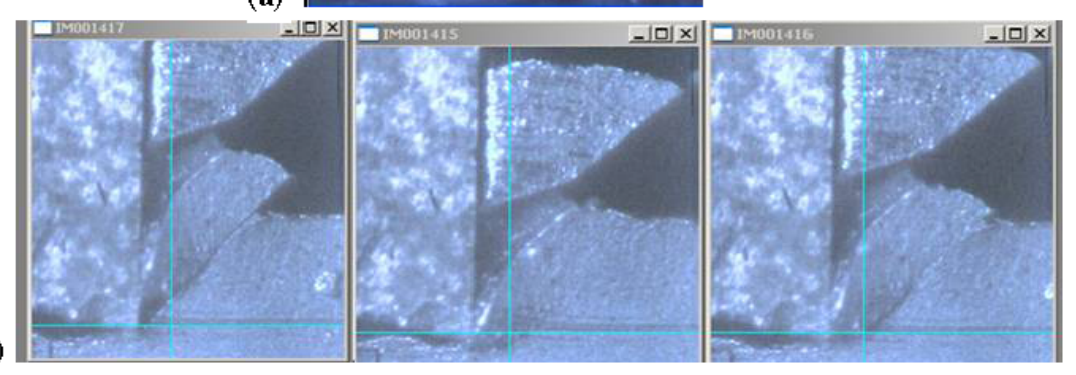

\section{Results and Discussion}

The obtained results are shown depending on whether one considers lubricated or dry machining, and the use of tools with or without coating. The calculation of the friction coefficient in various cases was also performed. The effects of the tool geometry and the cutting speed on machinability are analyzed. Also an attempt has been made to examine the effect of various process parameters on the 
chip morphology and tool wear during machining two different titanium micro-structures: Ti-6Al-4V and Ti-55531.

The effect of the tool geometry on the machinability is presented here with results on both alloys machined with TiAlN coated tools. The analysis of these results was performed with a comparison on the machinability of the alloys according to the cutting forces, friction and the specific energy of the machining.

\subsection{Cutting forces}

The cutting forces affect machining quality depending on cutting conditions, tool and workpiece materials. Thus, the measurements of forces give indications on machinability of the machined material. In addition to the friction at the tool/chip interface, cutting forces depend on two main factors: area of the primary and secondary shear planes, and shear strength of the work material at these planes [26,27].

Figures 6 and 7 illustrate cutting forces $\left(F_{\mathrm{c}}\right)$ and feed forces $\left(F_{\mathrm{a}}\right)$ generated during machining titanium alloys Ti-6Al-4V and Ti-55531. The evolution of machining efforts is plotted as a function of the cutting speed $V_{\mathrm{c}}$ and the considered tool geometry.

Figure 6. Cutting forces obtained for Ti-6Al-4V and Ti-55531 with tool geometry "B".

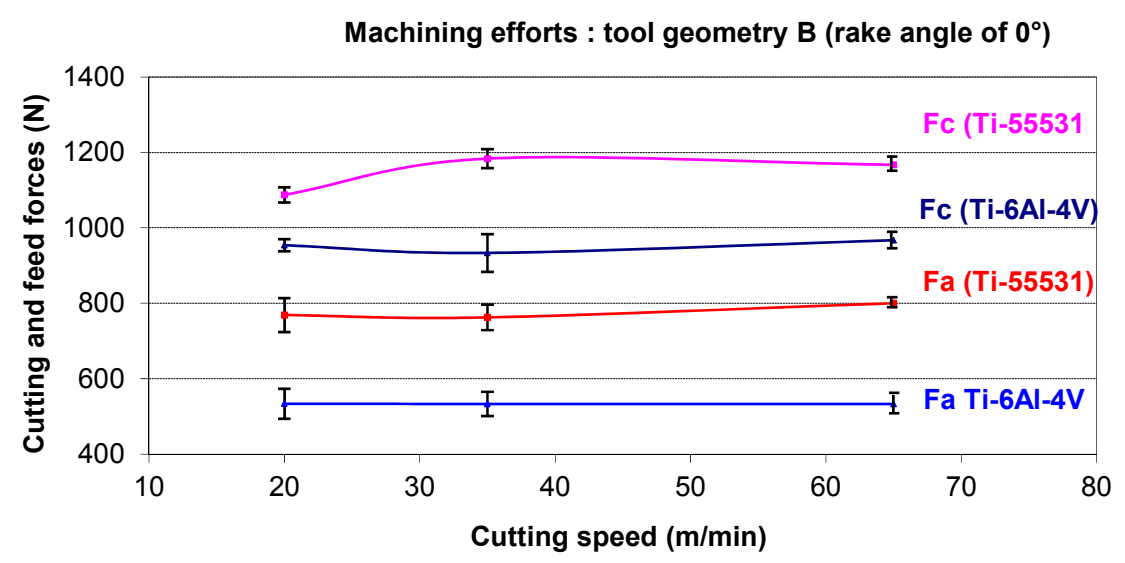

It can be observed from Figures 6 and 7 that $F_{\mathrm{c}}$ is the dominant force component. Therefore, the discussion on cutting forces is focused on the cutting force due the weak variation of feed forces. As seen in Figures 6 and 7, the feed force remains stable for all conditions.

First of all, it can be noted from Figure 6, there is a stabilization of cutting forces with high cutting speeds ( $35 \mathrm{~m} / \mathrm{min}$ and $65 \mathrm{~m} / \mathrm{min})$. However, a slight increase is still noticeable on the cutting force of the Ti-55531 alloy when the cutting speed increases from $20 \mathrm{~m} / \mathrm{min}$ to $65 \mathrm{~m} / \mathrm{min}$. During machining the Ti-6Al-4V alloy with a tool rake angle of $20^{\circ}$ (tool geometry "A") (Figure 7), a reduction of cutting forces is noticed when the cutting speed increases. This is quite normal considering the thermal softening of the material due to the temperature rise during machining. In other words, when the cutting speed increases, the temperature increases too and this is followed by a decrease in the yield stress level of the alloy. The material deforms under these conditions much more easily and without significant effort. This trend is expected because machining becomes more adiabatic and the heat generated in the shear zone cannot be conducted away during the very short interval of time during 
which the material passes through this zone. So, the temperature rise softens the material, aiding grain boundary dislocation and thus reducing cutting forces as seen from Figure 7.

Figure 7. Cutting forces obtained for Ti-6Al-4V and Ti-55531 with tool geometry "A".

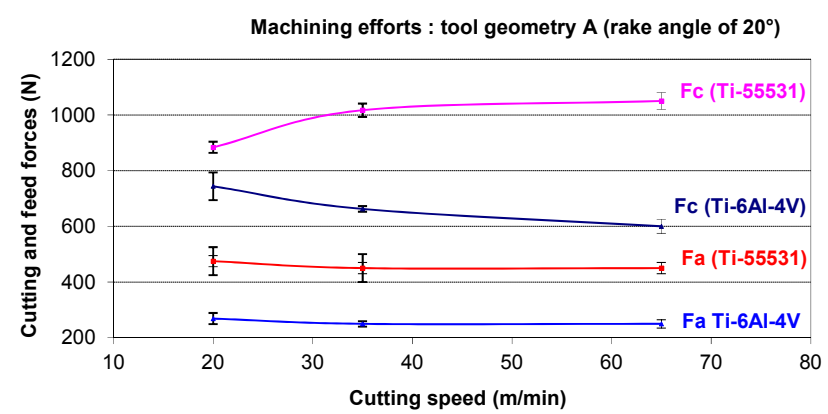

However, the cutting speed cannot be increased significantly pretext to further reducing the effort because of the significant increase (simultaneously) of the tool wear. On the other hand, an increase in the cutting force level of Ti-55531 with $20^{\circ}$ tool rake angle can be observed when increasing the cutting speed. This tendency can be explained by the high strain rate sensitivity of the Ti-55531 alloy.

According to Figure 6 the comparison between generated cutting forces shows a clear difference between Ti-6Al-4V and Ti-55531. This difference ranges from $12.3 \%-21.1 \%$ for the cutting force and from $30.1 \%-33.4 \%$ for the feed force. This result confirms the poor machinability (previously announced) of the Ti-55531 alloy compared to that of the Ti-6Al-4V under the same machining conditions. The trend given by tools with a rake angle of $0^{\circ}$ is confirmed by tools with a rake angle of $20^{\circ}$. The difference may reach $42.9 \%$ for some cutting conditions $\left(V=65 \mathrm{~m} / \mathrm{min}\right.$ and $\left.\alpha=20^{\circ}\right)$ (see Figure 7).

Also, it was found from Figures 6 and 7 that the cutting force obtained with the rake angle of $20^{\circ}$ was weak compared to that of machining with $0^{\circ}$ rake angle at all levels of considered parameters. This has been attributed to the fact that high values of the rake angle may reduce the friction along the cutting edge between tool and workpiece; see the evolution of the friction coefficient in the next subsection (Subsection 4.2).

\subsection{Friction Behavior at the Tool-Chip Interface}

In this section we focus on the friction, which is the manifestation of the mechanical energy dissipated in the contact between the tool and the workpiece in the form of heat which is responsible for the heating of the cutting edges.

Consequently, to understand physical phenomena during the chip formation, friction processes have to be investigated at the tool-chip interface. The friction co-efficient is an important parameter to characterize the nature of the tool-chip contact and tool wear depending on cutting conditions. According to the famous model of Merchant [16,28], the calculation of this parameter can be obtained using cutting forces measurements. In machining, the apparent friction coefficient (or average friction) is often defined as the ratio between the tangential force $\mathrm{Ft}$ and the normal force $F_{\mathrm{n}}[16,28]$.

$$
\mu=\frac{F_{t}}{F_{n}}=\frac{F_{a}+F_{c} \tan \alpha}{F_{c}-F_{a} \tan \alpha}
$$

where $\alpha$ is the rake angle; $F_{\mathrm{c}}$, cutting force; $F_{\mathrm{a}}$, feed force; $F_{\mathrm{t}}$, friction force; $F_{\mathrm{n}}$, normal force. 
Figures 8 and 9 show the variation of friction coefficient values at various cutting conditions. These values are calculated using Equation (1). The results of this study show that friction depends on the materials, the cutting temperature and machining conditions (cutting speed, tool geometry, etc.). In all tests, this parameter is more important with tool geometry "A" (rake angle $20^{\circ}$ ) compared to those with $0^{\circ}$ rake angle (tool geometry " $\mathrm{B}$ "). This is due to the reduction of the cutting temperature and contact length. This reduction is often followed by a reduction in frictional forces at the tool-workpiece interface. Low cutting temperatures reduce adhesion tendency of the cutting tool and promote contact area restriction. Reduction of the tool/chip contact length is expected to occur, as well as promotion of the plastic flow at the backside of the chip and overall reduction of temperature.

Figure 8. Evolution of the friction coefficient in the tool/chip interface. (Tool geometry "B", rake angle $0^{\circ}$ ).

Friction coefficient (tools rake angle of $0^{\circ}$ )

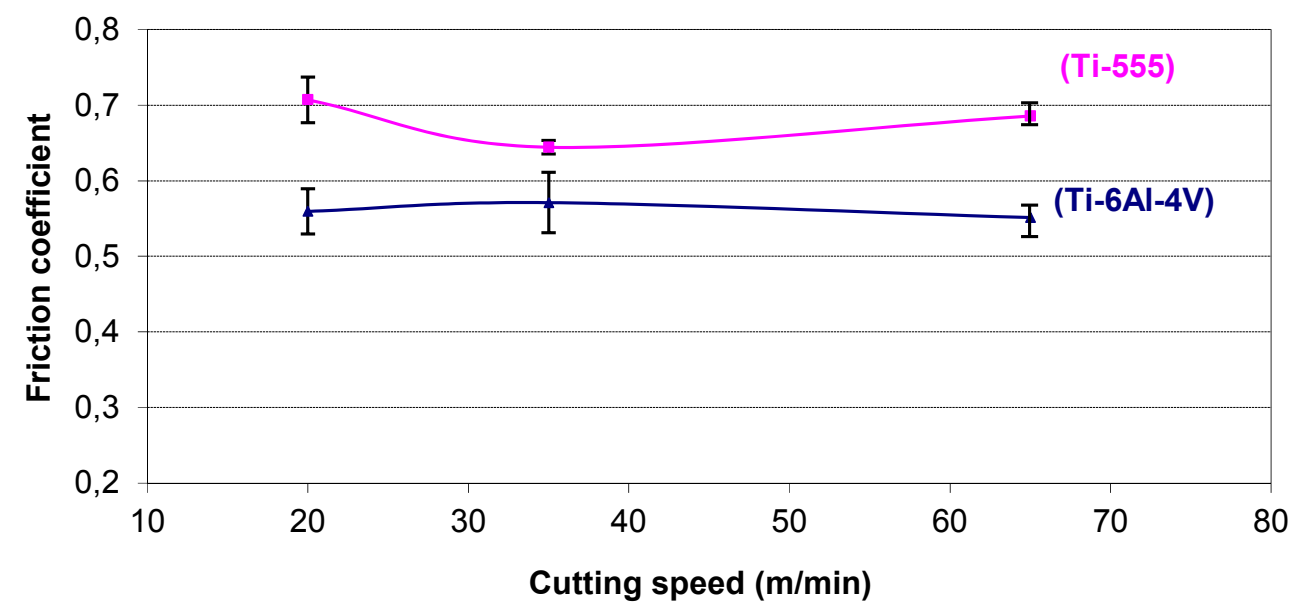

Figure 9. Evolution of the friction coefficient in the tool/chip interface. (Tool geometry "A", rake angle $20^{\circ}$ ).

Friction coefficient (tools rake angle of $20^{\circ}$ )

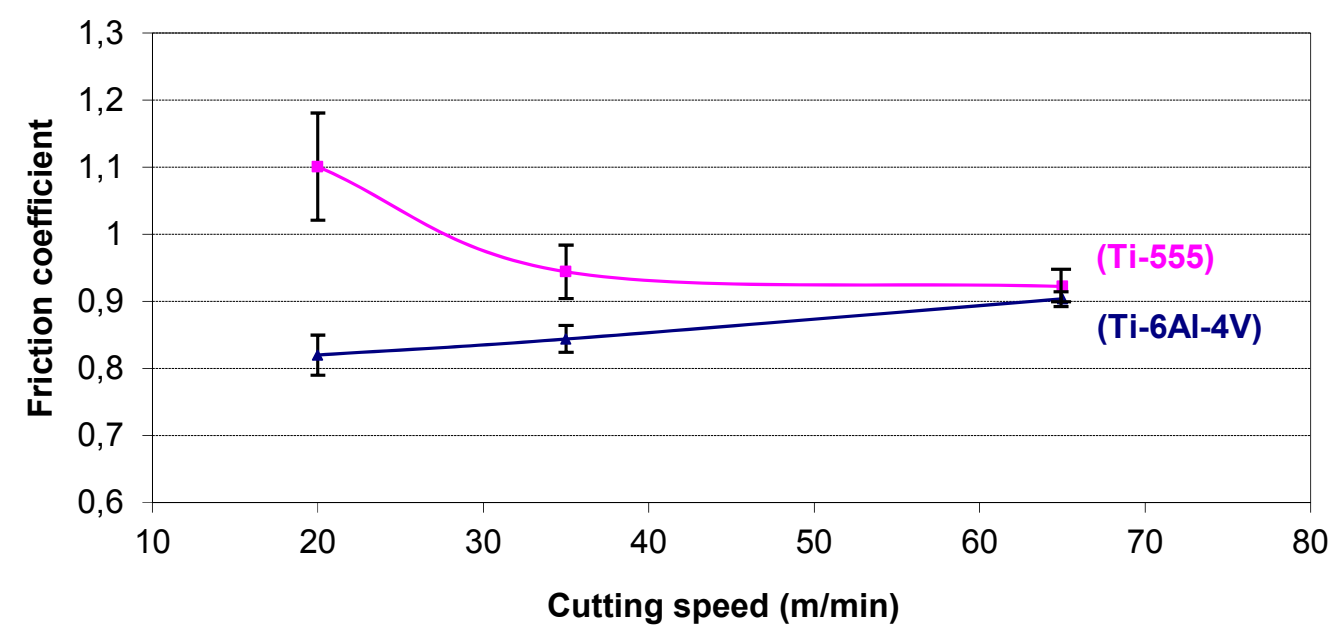

The results presented above (in Figures 8 and 9) show a higher friction coefficient for Ti-55531 compared to Ti-6Al-4V. Thus, the following assumptions can be presented: the contact area at the 
tool-chip interface can be considered as a sticking contact type for Ti-55531 in the case of machining with tools of $0^{\circ}$ rake angle. Therefore, a connection can be made between the nature of the contact (sticking) and the tendency of Ti-55531 to adhere to the cutting face of the tool. In contrast, the tool-chip contact can be of a sliding type in the case of Ti-6Al-4V because of the low values of friction (see Figure 8).

In the case of machining with tools of $20^{\circ}$ rake angle (Figure 9), the reduction in friction coefficient for the Ti-55531 indicates contact of the sliding type more than the sticking one. Contrary to this trend, increasing friction for the Ti-6Al-4V alloy indicates sticking contact. Also, the increase of the cutting speed (in particular for testing tool geometry $20^{\circ}$ ) involves stabilization of the friction at high cutting speeds (the friction is a decreasing function of the temperature when the cutting speed increases).

In conclusion, at constant cutting speed, titanium alloy Ti-55531 is more sensitive to adhesion phenomena than Ti-6Al-4V alloy. This may also explain the poor machinability noticed on this alloy.

\subsection{Chip Morphology of Titanium Alloys Ti-6Al-4V and Ti-55531}

During machining and under the action of the tool cutting edge, the workpiece material undergoes a strong compression and deforms plastically. An intense shear is generated between the tool tip engaged in the material and the workpiece. We analyzed in our investigations this area, called "primary shear zone", in which the first shear occurs and which induces chip formation.

The chip morphology gives crucial information because it incorporates the material response during machining (mechanical, thermal, thermo-viscoplastic, etc.) and shows the stability of the cutting operation. Moreover, the evolution of cutting forces shows a correlation with the morphology of produced chips. The chip segmentation for example, often leads to a reduction of cutting efforts and the tool-chip contact length. In general, the continuous chip is undesirable in industrial applications. This is due to the generated problems which significantly affect the machining conditions: damage of the cutting edge, forming a heap of material on the cutting area, etc.

The images obtained by the high speed camera (Figure 10a) during machining of Ti-6Al-4V show a segmented chip. To confirm this observation further investigation were carried out on chips collected after machining. The micrographs obtained on these chips show a fairly regular segmentation (Figure 10b). Between two consecutive segments of a single chip, the plastic deformation is very intense and localized in a thin zone of a few micrometers (Figure 11). This area where the plastic deformation is localized is known as adiabatic shear band; it is the seat of extreme shear. The thickness of the shear band was measured for different cutting conditions and its evolution was followed depending on the material nature and on the value of cutting speed. The conclusion of this analysis is that the increase of cutting speed means that the shear bands are more refined in the chip body (Figure 11). 
Figure 10. Ti-6Al-4V alloy chip formation (a) (by high speed camera), and morphology (b).

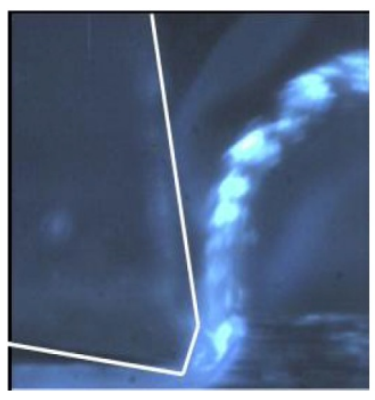

(a) Chip formation (Ti-6Al-4V, $20 \mathrm{~m} / \mathrm{min}$, rake angle $0^{\circ}$ )

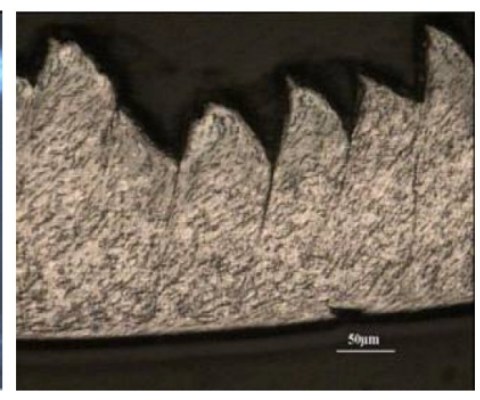

(b) Chip morphology (Ti-6Al-4V, $35 \mathrm{~m} / \mathrm{min}$, rake angle $0^{\circ}$ )

Figure 11. Evolution of the adiabatic shear band thickness depending on the cutting speed for Ti-6Al-4V. (a) $20 \mathrm{~m} / \mathrm{min}$, (b) $35 \mathrm{~m} / \mathrm{min}$, (c) $65 \mathrm{~m} / \mathrm{min}$. Tests without lubrication.
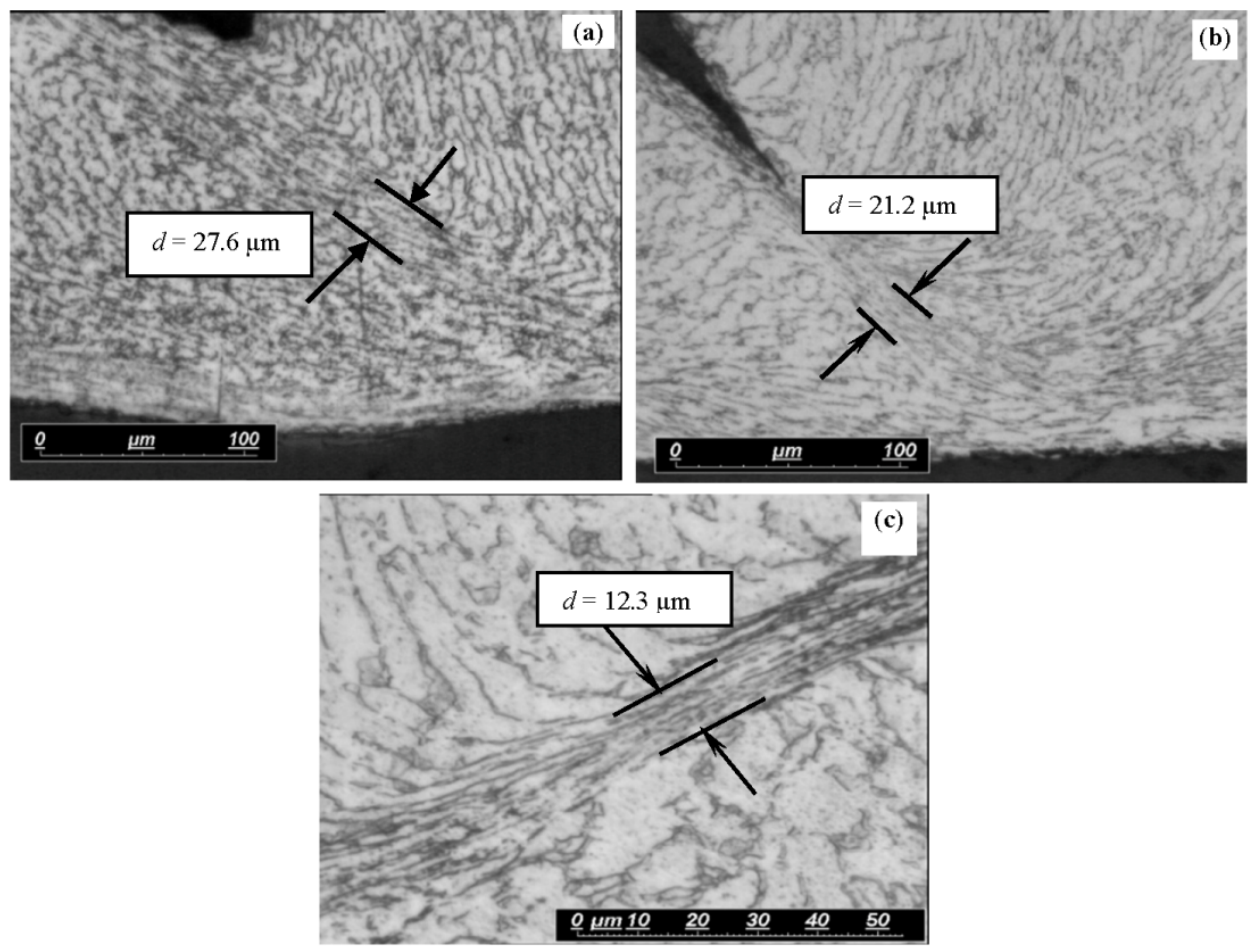

Unlike Ti-6Al-4V, Ti-55531 chips have a morphology slightly scalloped with a rather continuous nature. They are also characterized by highly irregular thicknesses. This morphology retains the same characteristics at different cutting speeds and for the different geometries tested (Figure 12).

Figure 13 shows the appearance of pronounced adiabatic shear bands without cracking or separation between the chip segments. So, the segmentation being synonymous with lower cutting efforts, during machining Ti-55531 alloy means cutting efforts will not decrease even if cutting speed increases. This explains the poor machinability of Ti-55531 compared to the Ti-6Al-4V alloy. 
Figure 12. Chip morphology of Ti-55531 (20 m/min, tool A).
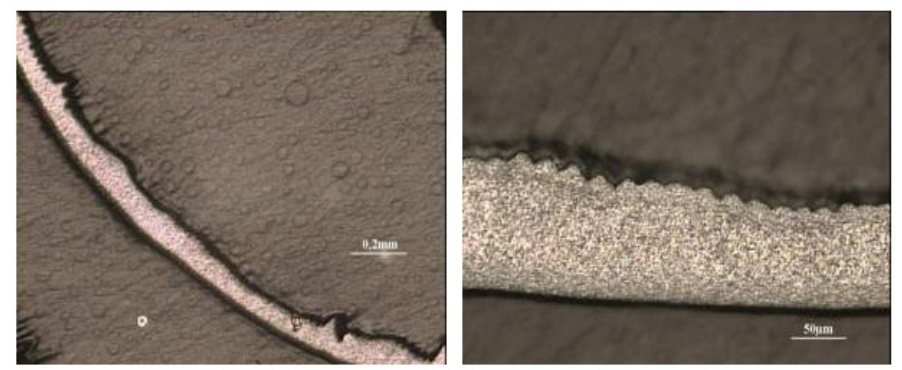

Figure 13. Chip morphology of Ti-55531 (35 m/min, tool A).

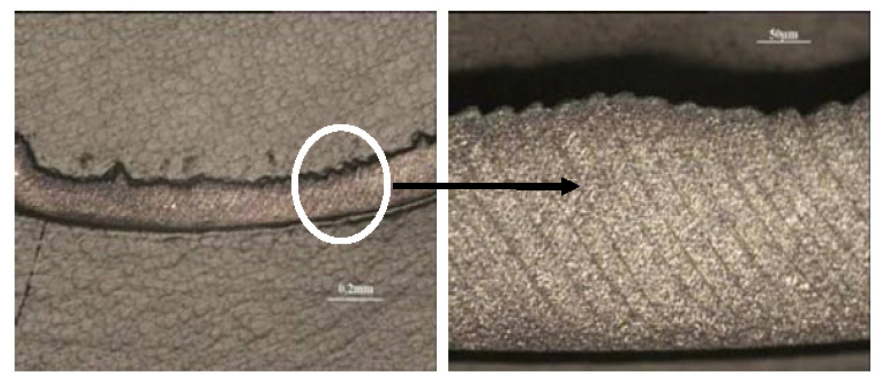

Finally, under the same machining conditions and tool geometries, it can be seen that Ti-6Al-4V forms segmented chips more easily than Ti-55531. This segmentation allows improved machinability resulting in lower cutting forces.

\subsection{Microstructure Effect}

Chips obtained after machining and presented in Figure 14 were mounted with epoxy so that they stood on their edge in order to make the cross section after polishing straight across their length. The polished chips were etched with Kroll's reagent to reveal their microstructures. Micrographs of examined chips in Figure 14 show clearly the deformation phenomenon inside the microstructure of both materials during the chip formation. However, the deformation process is different from one material to another. It can be noted here that both chips given by machining Ti-6Al-4V and Ti-55531 alloys were obtained with the same cutting conditions.

The examination of the deformed microstructure reveals very fine sizes of grains in the $\beta$ alloy (Ti-55531). In this material, the deformation process is localized in a very thin layer called primary shear zone while in the Ti-6Al-4V alloy the same process of deformation occurs in the whole microstructure, i.e., in $\alpha, \beta$ and $\alpha+\beta$ phases. Indeed, chips of the Ti-6Al-4V alloy have a very different microstructure compared to the initial Ti-6Al-4V alloy. For Ti-55531 chips, apart from the primary shear zone, there is a very similar microstructure to that observed in the initial Ti-55531 alloy. 
Figure 14. Microstructure of the chip material obtained after machining.

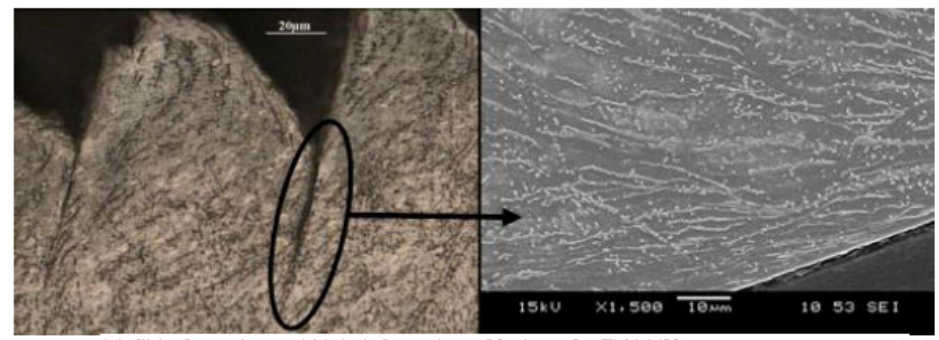

(a) Chip formation and high deformation of $\beta$ phase for Ti6 $14 \mathrm{~V}$

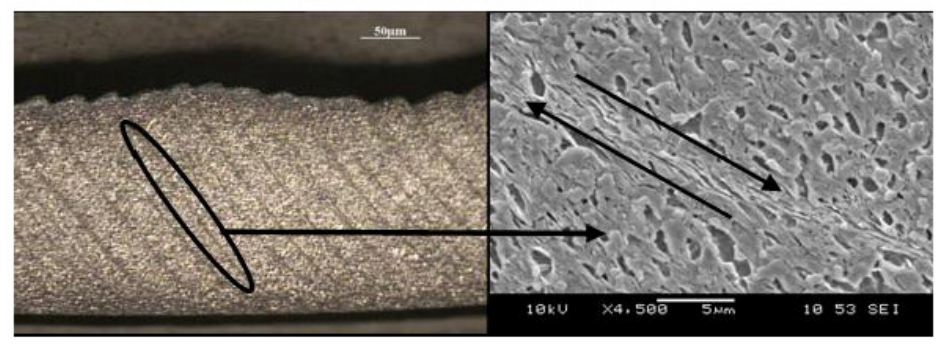

(b) Chip formation and very localized deformation of $\beta$ phase for Ti-55531

\section{Wear Mechanisms of Cutting Tools}

In this section the different modes of tool degradation have been analyzed when machining titanium alloys Ti-6Al-4V and Ti-55531. Wear can be discussed in relation to the nature of the material involved, its metallurgical and thermophysical characteristics, machining conditions and the tool coating. The wear analysis is based on observations of the scanning electron microscope (SEM, JEOL (EUROPE) SAS., Paris, France) equipped with an energy X-ray spectrometer (EDS, JEOL (EUROPE) SAS., Paris, France) in correlation with measurements obtained with an optical profilometer. The damage modes of tool characterization was conducted through the measurement of:

- the worn tool-chip contact length,

- the thickness and extent of the formed adhesion layers,

- the depth and width of the crater formed on the tool rake face.

The determination of the worn contact length was performed by analyzing the SEM micrographs of tool-chip contact zones. These areas have previously been identified by measuring the distance between the cutting edge and the limit of the worn portion on the interface. Furthermore, in-situ analysis (using a high speed camera CCD) has shown that the chip winding is forward of the tool. Thus, the footprint of the wear on the tool surface represents the contact between the latter and the chip being formed. Figure 15 summarizes the different values of the recorded worn contact length.

The results show that the increase of the cutting speed induces an increase of the worn contact length. In the case of Ti-6Al-4V the variation is more remarkable. For both tested geometries, it is around $45 \%$. This confirms the analysis of the heat-softening behavior of material. Indeed, and as mentioned above, Ti-6Al-4V has a lower thermal conductivity compared to Ti-55531 to high temperatures (around 30\%). The stored heat thus generates greater softening for Ti-6Al-4V than for Ti-55531. The contact between the tool and the Ti-6Al-4V alloy then extends over a larger area of the tool surface relative to the Ti-55531 alloy. For the Ti-55531 alloy, the variation of the contact area is about $25 \%$ when the cutting speed increases from $20-65 \mathrm{~m} / \mathrm{min}$. The presence of the betagenic element 
chromium in the Ti-55531 microstructure improves the deformation resistance of this alloy at high temperatures. Therefore, Ti-55531 machinability is degraded as a function of temperature.

Figure 15. Evolution of the tool-chip worn contact length.

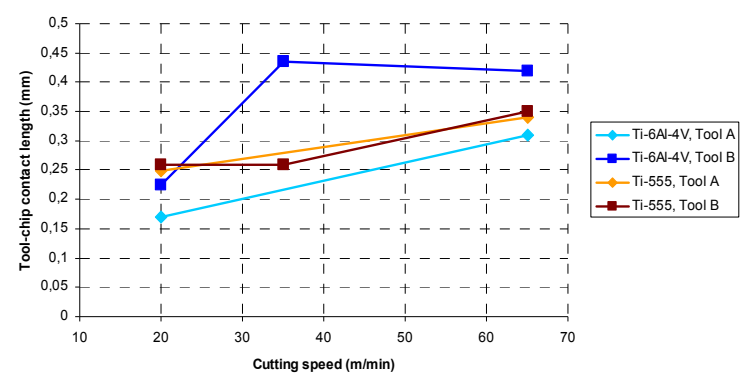

In conclusion, it can be said that the affected area by wear in the case of Ti-55531 is greater than in the case of Ti-6Al-4V at identical cutting conditions and tool geometry.

It has been observed from the SEM analysis in Figures 16 and 17 that the cutting tool encounters severe thermal and mechanical loading when machining titanium alloys. This can be supported by the level of the measured cutting temperature (about $750-800{ }^{\circ} \mathrm{C}$ for $V=65 \mathrm{~m} / \mathrm{min}$ ) and high recorded cutting forces (about $1000 \mathrm{~N}$ ). Also, other works previously showed that the cutting pressure can also attain large values (about 1-1.5 GPa), [10,29]. The high stresses and high temperatures generated close to the cutting edge have great influence on the tool wear rate and on tool life.

Figure 16. SEM images (BSE and SE micrographs) of the tool wear when machining Ti-6Al-4V and Ti-55531 alloys with different cutting speeds (rake angle $0^{\circ}$ ).

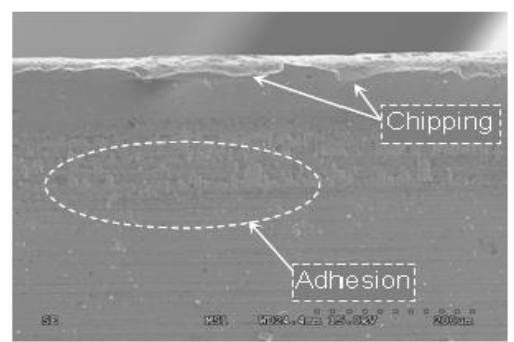

(a) SE micrograph (secondary electrons) for cutting tool (machining Ti-6A1-4V), $V \mathrm{c}=20 \mathrm{~m} / \mathrm{min}$

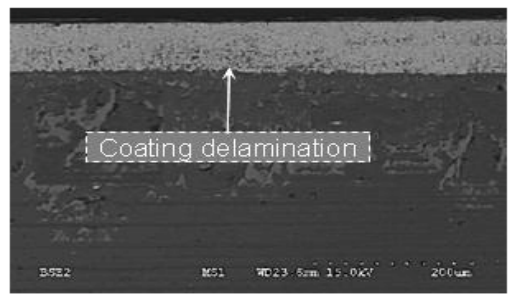

(c) BSE micrograph (Backscattered electrons) for cutting tool (machining Ti-6 A1 $4 \mathrm{~V}$ ), $V \mathrm{C}=65 \mathrm{~m} / \mathrm{min}$

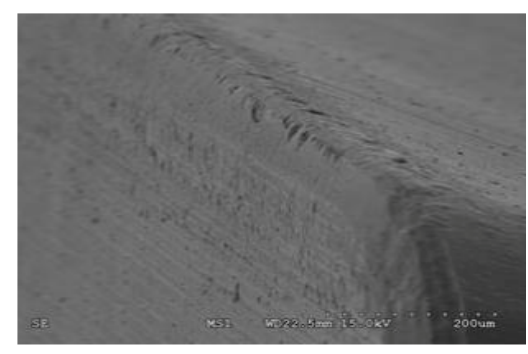

(b) $\mathrm{SE}$ micrograph (secondary dectrons) for cutting tool (machining Ti-55531), $V \mathrm{c}=20 \mathrm{~m} / \mathrm{min}$

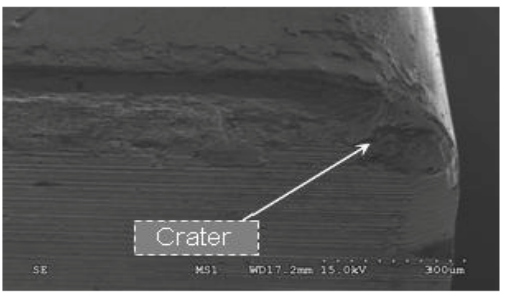

(d) SE micrograph (secondary electrons) for cutting tool (machining Ti-55531), $V \mathrm{C}=65 \mathrm{~m} / \mathrm{min}$

The tool geometry " $\mathrm{B}$ " has been designed primarily to give a negative rake angle to the front of the cutting edge (about $0.1 \mathrm{~mm}$ ). This allows steering the cutting forces inwardly of the tool (Figure 18). The aim of this treatment undergone by the cutting edge is to enhance the tool wear resistance. 
However, the test results showed a significant deterioration of machinability in terms of cutting forces compared to the tool geometry " $\mathrm{A}$ ".

Figure 17. SEM images of the tool wear when machining Ti-6Al-4V and Ti-55531 alloys (rake angle $20^{\circ}$ ).

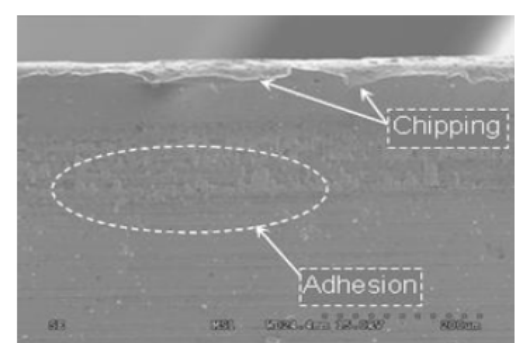

(a) SE micrograph (secondary electrons) for cutting tool (machining Ti-6Al-4V), $V \mathrm{c}=20 \mathrm{~m} / \mathrm{min}$

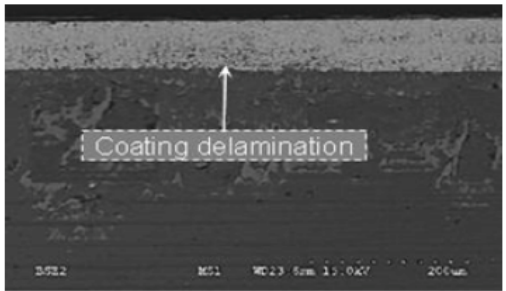

(c) BSE micrograph (Backscattered electrons) for cutting tool (machining $\mathrm{Ti}-6 \mathrm{~A} 1-4 \mathrm{~V}$ ), $V_{\mathrm{C}}=65 \mathrm{~m} / \mathrm{min}$

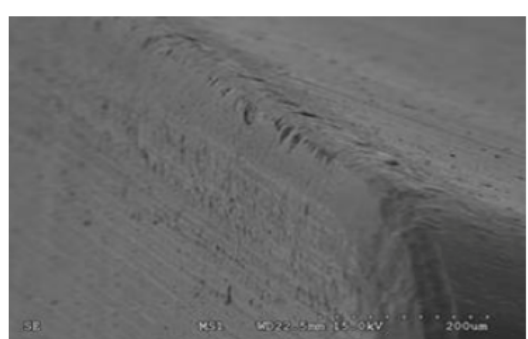

(b) SE micrograph (secondary electrons) for cutting tool (machining Ti-55531), $V \mathrm{c}=20 \mathrm{~m} / \mathrm{min}$

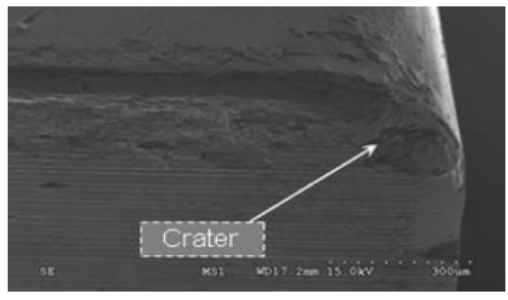

(d) SE micrograph (secondary electrons) for cutting tool (machining Ti-55531), $V \mathrm{c}=65 \mathrm{~m} / \mathrm{min}$

Figure 18. Orientation of machining efforts on a tool edge.

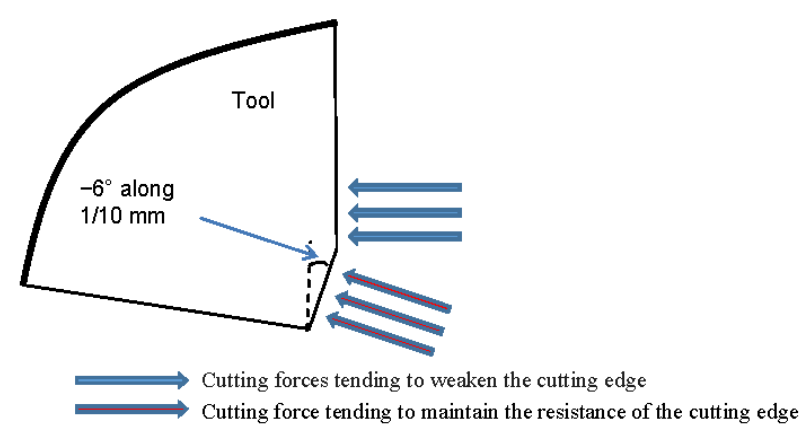

From Figure 19, at identical machining conditions, it can be noted that the extent of the negative rake angle of $0.1 \mathrm{~mm}$ is not degraded by the adhesion process but only by abrasion wear. The most tangible explanation of this observation is that this area of the tool displaces (or rejects) the material rather than machining. 
Figure 19. Adhesion extent on tool geometry $\mathrm{B}\left(V_{\mathrm{c}}=20 \mathrm{~m} / \mathrm{min}\right)$, (a) Ti-6Al-4V; (b) Ti-55531.

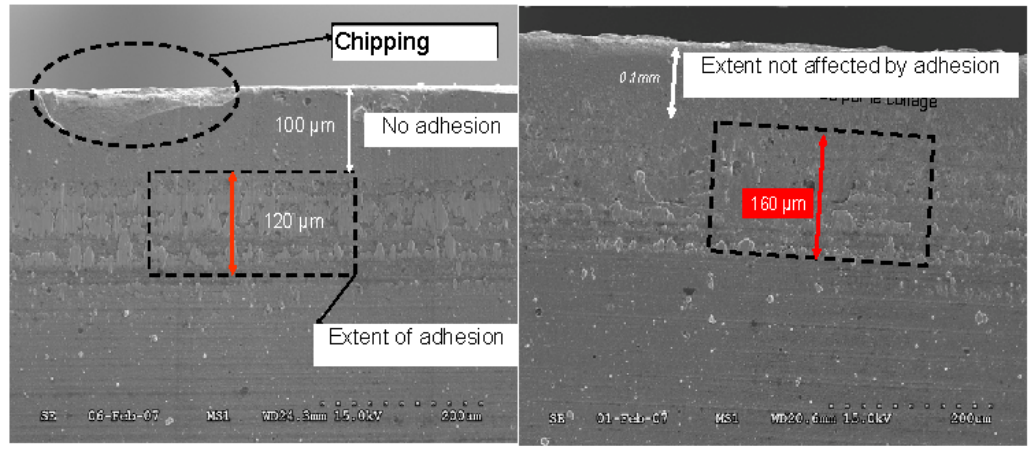

(a)

(b)

In the case of tools with $0^{\circ}$ rake angle, the extent of the area affected by the wear is greater for Ti-55531 than for Ti-6Al-4V. At $20 \mathrm{~m} / \mathrm{min}$ for example, it is about $120 \mu \mathrm{m}$ for the Ti-6Al-4V while about $160 \mu \mathrm{m}$ for Ti-55531 (Figure 19a,b). This is mainly due to the fact that the increase in cutting forces for the Ti-55531 generates higher stress on the cutting edge. The hardness of the material also contributes to the heavy wear edge. Micrographs also show delamination of the coating layer on the tool surface during machining Ti-6Al-4V at $65 \mathrm{~m} / \mathrm{min}$. This is not the case for the Ti-55531 alloy under the same cutting speed (Figure 16a-d).

The delamination phenomenon is difficult to analyze because it can have both thermal and mechanical origins. This is partly due to the complex interaction between various physical factors that control delamination: intrinsic properties of the coating, the tool and those of the interaction between the substrate, coating and workpiece. However, it is possible to attribute the origin of delamination to chemical reactions. During cutting of Ti-6Al-4V, adhesion occurring at the tool-chip interface is the main harbinger of the delamination problem.

At low cutting speeds, adhesive wear mode was observed during machining titanium alloys (Figure 16). The location of the adhesion wear is greater in the case of Ti-6Al-4V compared to Ti-55531. For Ti-55531, the wear results show that the predominant degradation process is abrasion wear (Figure 16b).

As shown by the EDS analysis illustrated in Figure 20, particle debris are deposited on the tool surface during machining Ti-6Al-4V as successive layers when chips scroll to the surface. This leads to the adhesive wear mode. The latter is highlighted by the change in the tool geometry and debonding of the coating (Figure 17c). 
Figure 20. Energy X-ray spectrometer (EDS) measurements of the adhered material (Ti-6Al-4V) on the rake face. $V=20 \mathrm{~m} / \mathrm{min}$, rake angle $0^{\circ}$.
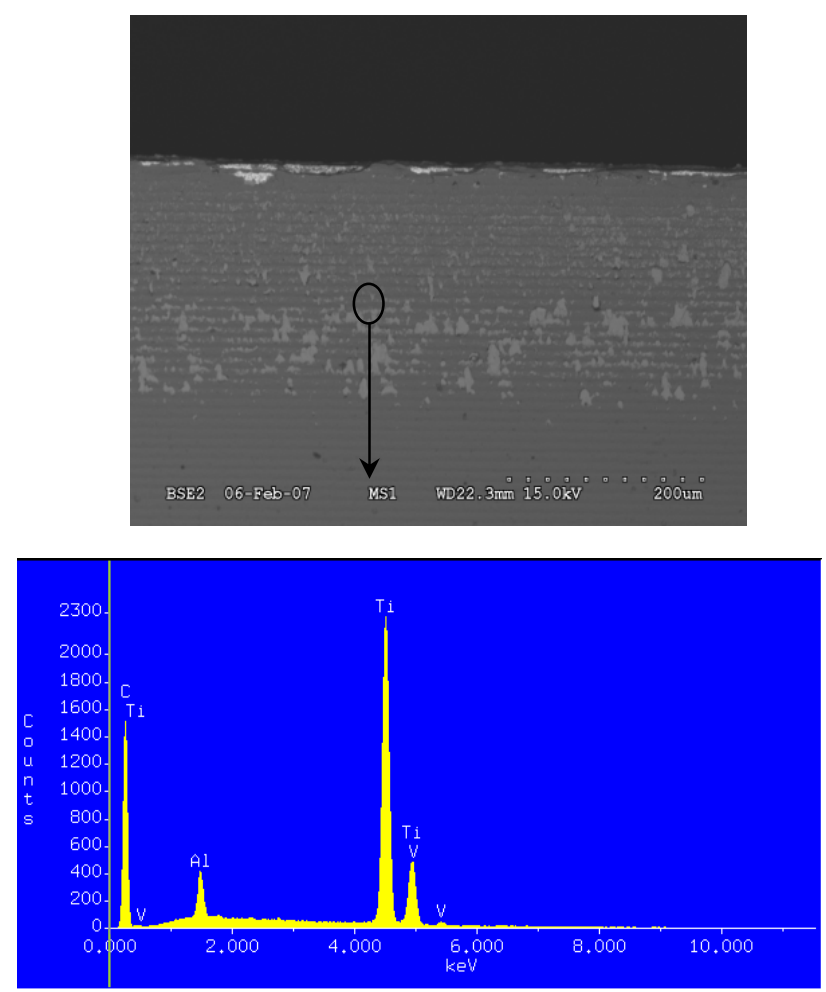

During machining Ti-55531 at $65 \mathrm{~m} / \mathrm{min}$, a process of cracking starts resulting in a collapse of the cutting edge (Figure 17d). This is produced by the combined effect of high pressures and large strain rates in the tool (substrate and coating). Adhesive wear layers on the tool surface were measured using a profilometer in the case of machining Ti-6Al-4V. Figure 21 shows the evolution of the adhesive layer extent depending on cutting speed.

Figure 21. Evolution of the adhesive layer extent on the tool surface during machining Ti-6Al-4V with different cutting speeds.

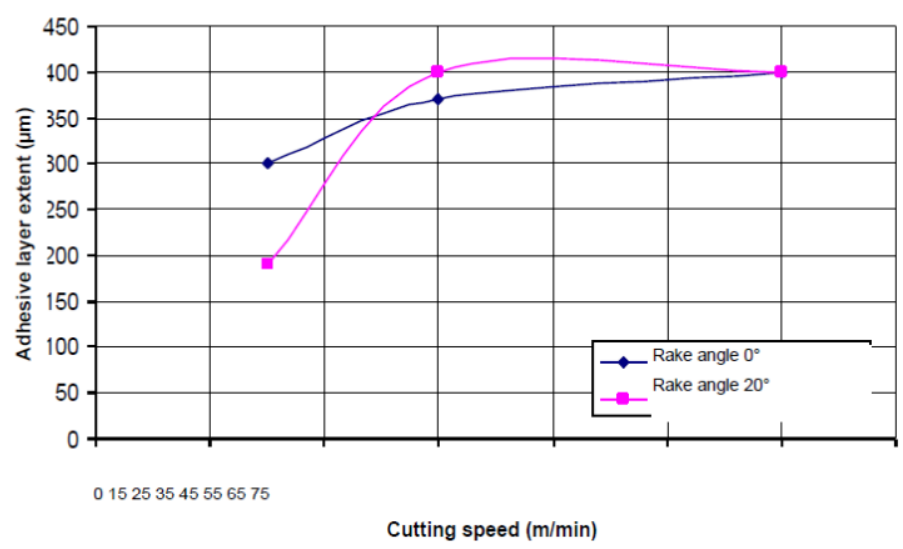

It appears from this result that the adhesive wear increases with the cutting speed and is stabilized at high speeds. This may be due to the diffusion process between titanium alloy and the cutting tool at the interface. In some cases and under the combined effect of pressure and temperature, welds are formed 
between tool and chip. With permanent mechanical stress (during machining), these welds are broken thereby causing chipping of the cutting surface. The irregularity on the tool surface can constitute attachment points for chip debris. By accumulating, they eventually form a detrimental macroscopic deposit on the cutting edge. This phenomenon has been observed for cutting tools when machining the Ti-6Al-4V alloy under low cutting speeds (see Figures 16a and 17a).

In the case of Ti-6Al-4V, the average grain size is about $10 \mu \mathrm{m}$ and the measured microhardness is in the range of $317 \mathrm{HV}_{0,2}$. For Ti-55531, the microstructure is homogeneous and the grain size is about $1 \mu \mathrm{m}$ with a microhardness of $379 \mathrm{HV}_{0,2}$. From a metallurgical point of view, the major difference between Ti-6Al-4V and Ti-55531 is due to fineness of the microstructure. This generally leads to a higher mechanical strength. However this will strongly influence the machinability of the machined material and then tool wear as confirmed by Powell and Duggan [30] and by Arrazola et al. in [31]. In addition, Ti-55531 is an alloy of the $\beta$-type (near- $\beta$ titanium alloy), with the presence of betagenic elements, such as chromium, for example, which limits the ability of the material to deform during machining.

Based on the results from the experimental tests we can give some ideas of how to improve the machining of the two alloys studied in this article. It is possible to increase the cutting speed in the case of machining Ti-6Al-4V, which causes increase in temperature at the interface tool/material and therefore a significant softening of the machined material. Consequently cutting efforts will be lower. This solution cannot be applied in the case of Ti-55531 because of its high strain rate sensitivity. On the other hand, the improvement of the machining of Ti-6Al-4V can be carried out by changing the geometry of the tool. Increasing rake angle facilitates chip flow; this will cause reduction in cutting efforts and pressure. This improvement can also be applied to the machining of Ti-55531 alloy.

\section{Conclusions}

In this research work, a detailed experimental approach for the comprehension of machining titanium alloys has been presented. Several analyzes (SEM, EDS, Infrared camera, high-speed camera $\mathrm{CCD}$ and profilometer analysis) confirmed that differences in machinability and microstructure of tested titanium alloys can have an important impact on tool wear. The low machinability of titanium alloys due to the low thermal conductivity and high microhardness of these materials leads to severe and premature tool wear. The machining of titanium alloy Ti-55531 has been compared with that of Ti-6Al-4V alloy. To do this study, the mechanical, thermal, metallurgical and physico-chemical aspects were analyzed in depth.

During the evolution of the machining efforts depending on cutting conditions and tool geometry, a decrease of cutting forces is noted for the case of Ti-6Al-4V when the cutting speed increases. This decrease is due to the thermal softening of the material under the effect of plastic deformation and cutting temperature. In other words, during the machining of Ti-6Al-4V, its yield stress decreases and therefore improves the machinability for this material. For Ti-55531, this reduction has not been clearly identified. Unlike the Ti-6Al-4V alloys, the chip morphology of Ti-55531 shows a work hardening behavior. This means that flow stress increases during machining making its machinability more difficult. 
From a metallurgical point of view, the major difference between Ti-6Al-4V and Ti-55531 is the fineness of the microstructure. The latter is automatically accompanied by higher strength, better ductility and toughness. It can therefore be said that Ti-55531 has better fatigue resistance which greatly penalizes its machinability. Another difference from Ti-55531 relative to Ti-6Al-4V is the fact that the microstructure of Ti-55531 contains a volume fraction of the larger $\beta$ phase. This increases its hardness while also reducing its machinability.

Results have also shown that the friction between the tool and the workpiece is close to one for the case of Ti-55531 alloy compared to Ti-6Al-4V. This means that during Ti-55531 machining the contact at the chip-tool interface is of a sticky type, thereby giving impetus to the Ti-55531 alloy to more easily adhere to the cutting tool face. This type of contact also influences the thermal field which is greater in the case of Ti-55531 (temperature for Ti-55531 about $800{ }^{\circ} \mathrm{C}$, for Ti-6Al-4V about $670^{\circ} \mathrm{C}$ ). In addition, at the high temperatures, Ti-55531 alloy conducts heat better than the Ti-6Al-4V alloy. The low thermal conductivity of Ti-6Al-4V promotes chip segmentation and therefore the reduction of machining efforts. For the Ti-55531 alloy, its higher conductivity allows it to further evacuate the stored heat, but at the same time it decreases its ability to soften and thereby deteriorates its machinability. Thus, it has been found that the area affected by the wear in the case of Ti-55531 is greater than in the case of Ti-6Al-4V under the same machining conditions and for the same tool geometry. The current study also showed that the tool geometry has a significant influence on the machinability of both titanium alloys. With a rake angle of $0^{\circ}$, the difference of machinability is only about $12 \%$ between Ti-55531 and Ti-6Al-4V and remains constant regardless of the cutting speed. With geometry of $20^{\circ}$, this difference is greater and reached high levels for high cutting speeds (approximately $34.7 \%$ to $65 \mathrm{~m} / \mathrm{min}$ ).

\section{Conflicts of Interest}

The authors declare no conflict of interest.

\section{References}

1. Boyer, R.R. An overview on the use of titanium in the aerospace industry. Mater. Sci. Eng. 1996, 213, 103-114.

2. Ginting, A.; Nouari, M. Surface integrity of dry machined titanium alloys. Int. J. Mach. Tools Manuf. 2009, 49, 325-332.

3. Clément, N.; Lenain, A.; Jacques, P.J. Mechanical property optimization via microstructural control of new metastable beta titanium alloys. JOM 2007, 59, 50-53.

4. Clement, N.; Lenain, A.; Veron, M.; Jacques, P.J. Characterization of the interactions between recrystallization and precipitation in a two phase $\beta$-metastable Titanium Alloy. Proceeding of an International Conference on Solid-Solid Phase Transformations in Inorganic Materials; Howe, J.M., Laughlin, D.E., Lee, J.K., Dahmen, U., Soffa, W.A., Eds.; Wiley: Phoenix, AZ, USA, 2005; pp. 603-608.

5. Nouari, M.; Ginting, A. Wear characteristics and performance of multi-layer CVD-coated alloyed carbide tool in dry end milling of titanium alloy. Surf. Coat. Technol. 2006, 200, 5663-5676. 
6. Ginting, A.; Nouari, M. Experimental and numerical studies on the performance of alloyed carbide tool in dry milling of aerospace material. Int. J. Mach. Tools Manuf. 2006, 46, 758-768.

7. Nouari, M.; Makich, H. Experimental investigation on the effect of the material microstructure on tool wear when machining hard titanium alloys: Ti-6Al-4V and Ti-555. Int. J. Refract. Metals Hard Mater. 2013, 41, 259-269.

8. Komanduri, R.; Turkovich, B.F.V. New observations on the mechanism of chip formation when machining titanium alloys. Wear 1981, 69, 179-188.

9. Ginting, A.; Nouari, M. Optimal cutting conditions when dry end milling the aeroengine material Ti-6242S. J. Mater. Process. Technol. 2007, 184, 319-324.

10. Ezugwu, E.O.; Wang, Z.M. Titanium alloys and their machinability-A review. J. Mater. Process. Technol. 1997, 68, 262-274.

11. Subramanian, S.V.; Ingle, S.S.; Kay, D.A.R. Design of coatings to minimize tool crater wear. Surf. Coat. Technol. 1993, 61, 293-299.

12. Bouchnak, T.B. Etude du comportement en sollicitations extrêmes et de l'usinabilité d'un nouvel alliage de titane aéronautique. Ph.D. Thesis, ParisTech, École Nationale Supérieure d'Arts et Métiers, 2010.

13. Fanning, J.C. Properties of TIMETAL 555 (Ti-5Al-5Mo-5V-3Cr-0.6Fe). JMEPEG 2005, 14, 788-791.

14. Nyakana, S.L.; Fanning, J.C.; Boyer, R.R. Quick reference guide for $\beta$ titanium alloys in the 00s. JMEPEG 2005, 14, 799-811.

15. Semiatin, S.L.; Seetharaman, V.; Ghosh, A.K. Plastic flow, microstructure evolution, and defect formation during primary hot working of titanium and titanium aluminide alloys with lamellar colony microstructures. Philos. Trans. R. Soc. A 1999, 357, 1487-1512.

16. Jackson, M.; Dashwood, R.; Christodoulou, L.; Flower, H. The microstructural evolution of near beta alloy Ti-10V-2Fe-3Al during subtransus forging. Metal. Mater. Trans. A 2005, 36, 1317-1327.

17. Benedetti, M.; Fontanari, V. The effect of bi-modal and lamellar microstructures of Ti-6Al-4V on the behaviour of fatigue cracks emanating from edge-notches. Fatigue Fract. Eng. Mater. Struct. 2004, 27, 1073-1089.

18. Nouari, M.; Calamaz, M.; Girot, F. Mécanismes d'usure des outils coupants en usinage à sec de l'alliage de titane aéronautique Ti-6Al-4V. C.R. Mécanique 2008, 336, 772-781.

19. Devillez, A.; Schneider, F.; Dominiak, S.; Dudzinski, D.; Larrouquere, D. Cutting forces and wear in dry machining of Inconel 718 with coated carbide tools. Wear 2007, 262, 931-942.

20. Singh Gill, S.; Singh, R.; Singh, H.; Singh, J. Investigation onwear behaviour of cryogenically treated TiAlN coated tungsten carbide inserts in turning. Int. J. Mach. Tools Manuf. 2011, 51, $25-33$.

21. Castanho, J.; Vieira, M. Effect of ductile layers in mechanical behaviour of TiAlN thin coatings. J. Mater. Process. Technol. 2003, 143, 352-357.

22. Battagliaa, J.L.; Coisb, O.; Puigsegura, L.; Oustaloupb, A. Solving an inverse heat conduction problem using a non-integer identified model. Int. J. Heat Mass Transf. 2001, 44, 2671-2680. 
23. Puerta Velasquez, J.D.; Bolle, B.; Chevrier, P.; Geandier, G.; Tidu, A. Metallurgical study on chips obtained by high speed machining of a Ti-6 wt.\%Al-4 wt.\%V alloy. Mater. Sci. Eng. A 2007, 452-453, 469-474.

24. He, Y. Rapid thermal conductivity measurement with a hot disk sensor: Part 1. Theoretical considerations. Thermochim. Acta 2005, 436, 122-129.

25. Abdel-Aal, H.A.; Nouari, M.; El Mansori, M. Tribo-energetic correlation of tool thermal properties to wear of WC-Co inserts in high speed dry machining of aeronautical grade titanium alloys. Wear 2009, 266, 432-443.

26. Merchant, E. Mechanics of the metal cutting process II. Plasticity conditions in orthogonal cutting. J. Appl. Phys. 1945, 16, 318-324.

27. Diniz, A.E.; Micaroni, R. Cutting conditions for finish turning process aiming: the use of dry cutting. Int. J. Adv. Manuf. Technol. 2002, 42, 899-904.

28. Merchant, E. Mechanics of the metal cutting process I. Orthogonal cutting and a type 2 chip. J. Appl. Phys. 1945, 16, 267-275.

29. Komanduri, R. Some clarifications on the mechanics of chip formation when machining titanium alloys. Wear 1982, 76, 15-34.

30. Powell, B.E.; Duggan, T.V. Predicting the onset of high cycle fatigue damage: an engineering application for long crack fatigue threshold data. Int. J. Fatigue 1986, 8, 187-194.

31. Arrazola, P.-J.; Garay, A.; Iriarte, L.-M.; Armendia, M.; Marya, S.; le Maître, F. Machinability of titanium alloys (Ti6Al4V and Ti555.3). J. Mater. Process. Technol. 2009, 209, 2223-2230.

(C) 2014 by the authors; licensee MDPI, Basel, Switzerland. This article is an open access article distributed under the terms and conditions of the Creative Commons Attribution license (http://creativecommons.org/licenses/by/3.0/). 